\title{
Feasibility Study on the Use of Probabilistic Migration Modeling in Support of Exposure Assessment from Food Contact Materials
}

\author{
Maria F. Poças, ${ }^{1,4 *}$ Jorge C. Oliveira, ${ }^{2}$ Rainer Brandsch, ${ }^{3}$ and Timothy $\mathrm{Hogg}^{4}$
}

\begin{abstract}
The use of probabilistic approaches in exposure assessments of contaminants migrating from food packages is of increasing interest but the lack of concentration or migration data is often referred as a limitation. Data accounting for the variability and uncertainty that can be expected in migration, for example, due to heterogeneity in the packaging system, variation of the temperature along the distribution chain, and different time of consumption of each individual package, are required for probabilistic analysis. The objective of this work was to characterize quantitatively the uncertainty and variability in estimates of migration. A Monte Carlo simulation was applied to a typical solution of the Fick's law with given variability in the input parameters. The analysis was performed based on experimental data of a model system (migration of Irgafos 168 from polyethylene into isooctane) and illustrates how important sources of variability and uncertainty can be identified in order to refine analyses. For long migration times and controlled conditions of temperature the affinity of the migrant to the food can be the major factor determining the variability in the migration values (more than $70 \%$ of variance). In situations where both the time of consumption and temperature can vary, these factors can be responsible, respectively, for more than $60 \%$ and $20 \%$ of the variance in the migration estimates. The approach presented can be used with databases from consumption surveys to yield a true probabilistic estimate of exposure.
\end{abstract}

KEY WORDS: Exposure assessment; food packaging; migration; probabilistic modeling

\section{INTRODUCTION}

There is an increasing interest in probabilistic approaches for quantifying variability and

${ }^{1}$ Packaging Department, Biotechnology College, Portuguese Catholic University, Rua Dr. António Bernardino de Almeida, 4200-072 Porto, Portugal.

${ }^{2}$ Process and Chemical Engineering Department, University College Cork, Cork, Ireland.

${ }^{3}$ MDCTec Ltd ZN Gilching, Untere Laeng 8c, 82205 Gilching, Germany.

${ }^{4} \mathrm{CBQF}$, Biotechnology College, Portuguese Catholic University, Rua Dr. António Bernardino de Almeida, 4200-072 Porto, Portugal.

* Address correspondence to Maria F. Poças, Packaging Department, Biotechnology College, Portuguese Catholic University, Rua Dr. António Bernardino de Almeida, 4200-072 Porto, Portugal;mfpocas@esb.ucp.pt. uncertainty in exposure and risk assessment, especially for refined assessments. ${ }^{(1)}$ They have been used for the assessment of exposure to food additives, pesticides, and other contaminants and their application in exposure assessment of substances migrating from packaging has also been gaining increasing interest. ${ }^{(2)}$ Probabilistic models were applied to estimate the short-term exposure of U.K. consumers to residual bisphenol-A-diglycidyl-ether (BADGE) from can coatings of canned foods, ${ }^{(3,4)}$ to di-2-ethylhexyl-adipate (DEHA) styrene ${ }^{(3)}$ from several packaging systems, and to a generalized migrant from coated metal cans. ${ }^{(5)}$

Exposure to chemicals migrating from packaging ( $\mathrm{mg} /$ person/day) can be expressed as a function of two terms: (1) migration $\left(\mathrm{mg} / \mathrm{kg}_{\text {food }}\right)$, that 
is, the concentration of the chemical that has migrated into the food and (2) food consumption $\left(\mathrm{kg}_{\text {food }} /\right.$ person/day) representing the intake of food packed in a certain type of packaging system that contains the migrating chemical, according to Equation (1):

$$
\text { Exposure }=\text { Migration } \times \text { Food Consumption } .
$$

The availability of reliable data to describe the two terms of the exposure in Equation (1) has been addressed before. ${ }^{(2)}$ Many of the studies reported apply the probabilistic approach to the "Food Consumption" term of the exposure (Equation (1)) and rely on single-point estimates for the "Migration" term using average, worst-case, or maximum legal values. Those analyses do not account for the variability that can be expected in migration values due to heterogeneity in the packaging system, in the composition and structure of the food product, or for uncertainty regarding, for example, the temperature along the distribution chain, different shelf life, and time of consumption of each different package. ${ }^{(2)}$ A major source of uncertainty is the lack of information on the packaging formulation corresponding to the different foods as this determines the presence and concentration of the chemical and influences the potential for migration into the type of food. ${ }^{(2)}$

This work is devoted to the term of the equation describing migration or concentration of the contaminant in the food. The lack of such data has been referred to as a limitation of exposure and risk assessments. ${ }^{(6,7)}$

Concentration data may be obtained from monitoring levels of the chemical in real food systems collected from the market shelves. This approach yields a realistic picture, and it is followed by national safety surveillance schemes, but requires a considerable analytical effort that is not free from problems caused by the complexity of food matrices. The level of migration may also be obtained experimentally by testing packages not previously used with food simulants. Alternatively, predictive mathematical models can be used to estimate migrant concentration data for different packaging formats and food products. These models can be deterministic (based on a theory describing a physical-chemical phenomenon), empirical (based on equations that yield a good fit to experimental data regardless of any physical meaning of the constants of the model), stochastic, or probabilistic, including the uncertainty and variabil- ity in the system parameter. ${ }^{(8)}$ The latter was followed in this work: each variable and parameter of the migration model described by classical transport and mass balance equations was replaced by a distribution of values resulting in a distribution of contamination values accounting for variability and uncertainty. These generated data, describing the range and probability of occurrence of the concentration values, can then be used together with food consumption data in Equation (1) to estimate exposure. A few previously reported studies with a similar approach to generate a distribution of values of concentration in food from a stochastic resolution of dimensionless mass-transport equations followed an elaborate mathematical procedure, requiring a numerical solution of the governing equations. ${ }^{(7,9,10)}$ In this work, analytical solutions of the transport equations are used combined with a userfriendly software supported by Excel (Microsoft Co., Redmond, WA). This provides a more manageable approach.

Frequently, there is only limited information on the variability and uncertainty of the model parameters because their determination requires a considerable experimental effort. A stochastic model to predict diffusion coefficients of the migrant in polyolefins was proposed before: a log-normal distribution to describe the diffusion coefficient, as a function of the migrant molar mass, was derived from a large number of experimental data published in the literature obtained in different experimental conditions. ${ }^{(11)}$ This distribution function is then applied to Equation (1) to derive a distribution of migration values. That analysis assumed a constant value for partition coefficient and temperature and did not consider variability in the packaging geometry parameters such as thickness and contact surface area. ${ }^{(11)}$ The objective of this work was to characterize quantitatively the uncertainty and variability in estimates of migration of a specific additive from a particular package considering the distributions of values of the model variables (packaging geometry, equilibrium concentration, and migration time) and model parameters (mass-transfer coefficients of diffusion and partition). The effect of temperature on these parameters was also considered. The distributions were determined experimentally for a food-packaging additive typically used in polyolefin packaging applications. Propagation of variability/uncertainty through the mathematical model was performed by Monte Carlo (MC) simulation. 


\section{MATERIALS AND METHODS}

\subsection{Experimental Determinations}

\subsubsection{Kinetic Experiments}

Experimental results obtained for migration of the antioxidant Irgafos 168 (CAS 31570-04-4) from yogurt bottles were used in the work. The bottles were made of high-density polyethylene (HDPE B6246 SABIC $\left.{ }^{(}\right)$and supplied blow-molded by Logoplaste (Portugal). Irgafos 168 has a tolerable daily intake (TDI) of $1 \mathrm{mg} /$ day.kg $_{\mathrm{bw}}$. The initial concentration of the migrant in the polymer was $707 \mathrm{mg} / \mathrm{kg}$.

Nine independent kinetic experiments were conducted to determine the mass-transfer parameters and the variability that can be expected in the results. The bottles were cut to obtain specimens (squared pieces) to be immersed in isooctane at $40{ }^{\circ} \mathrm{C}$. The pieces had an average surface area of $34 \mathrm{~cm}^{2}$ and an average thickness of $578 \mu \mathrm{m}$. Each specimen was placed in a glass jar with $100 \mathrm{~mL}$ isooctane with internal standard at a concentration of $10 \mathrm{mg} / \mathrm{L}$. This yields a contact surface area to volume ratio of $68 \mathrm{~cm}^{2} / 100 \mathrm{~mL}$. The ratio referred in the EN 1186 for immersion tests is $1 \mathrm{dm}^{2} / 100 \mathrm{~mL}$ for aqueous or $1 \mathrm{dm}^{2} / 50 \mathrm{~mL}$ for fat alternatives. The jars were stored at $40^{\circ} \mathrm{C}$ and an aliquot of $100 \mu \mathrm{L}$ was collected from each jar for gas chromatography analysis (GC-MS). The experiments at $23{ }^{\circ} \mathrm{C}$ and $8{ }^{\circ} \mathrm{C}$ were conducted with five replicates each.

Irgafos 168 is a phosphite additive that can oxidize to phosphate during the plastic processing and after migration. Both forms were considered and quantified by GC-MS through a calibration curve with five calibration standard solutions $(0-60 \mathrm{mg} / \mathrm{L})$. Standard solutions were injected in duplicate.

\subsubsection{Chromatographic Conditions}

Chromatograph Varian CP-3800 with mass selective detector (MS) 1200L Quadrupole; ionization mode: electronic impact $70 \mathrm{eV}$; scan model SIM (m/z 235 and 250 ions - internal standard $(\mathrm{m} / \mathrm{z} 147$ and 441 ions)_Irgafos 168, m/z 647 and 662 ions-oxidized form of Irgafos 168), and

(1) column: VF-5MS $(30 \mathrm{~m} \times 0.25 \mathrm{~mm}, 0.25 \mu \mathrm{m})$,

(2) temperature of injector: $320^{\circ} \mathrm{C}$,

(3) oven temperature: $50{ }^{\circ} \mathrm{C}$ during $2 \mathrm{~min}$; $15^{\circ} \mathrm{C} / \mathrm{min}$ up to $320^{\circ} \mathrm{C} ; 320^{\circ} \mathrm{C}$ for $10 \mathrm{~min}$,

(4) volume injected: $1 \mu \mathrm{L}$ : split: splitless (splitless time: $0.50 \mathrm{~min}$ ).

\subsubsection{Estimation of Mass-Transfer Coefficients (Diffusion and Partition)}

The appropriate analytical solution of Fick's second law (2) was fitted to each set of data by nonlinear regression to yield the best parameters for equilibrium concentration $\left(C_{\infty}\right)$ and diffusion coefficient $\left(D^{P}\right)$, with the last squares method (software Statistica, StatSoft, Inc., Tulsa, OK, USA). The partition coefficient $\left(K_{P}^{F}\right)$ was calculated from the mass balance with concentrations found experimentally at the final contact time.

\subsection{Probabilistic Analysis}

EFSA describes the main steps of a general probabilistic analysis as: ${ }^{(13)}$

1. definition of the scenario and the structure of the model;

2. identification of which inputs are variable and/or uncertain;

3. identification of important dependencies between inputs;

4. specification of distributions and dependencies to represent variability and uncertainty of the model inputs;

5. propagation of the variability and uncertainty through the exposure model and quantification of the resulting variability and uncertainty in the output;

6. sensitivity analysis to examine the contribution of each model input to variability and uncertainty in the output.

These steps were followed in this study and the step of specification of the probability distribution functions is a key one.

The model structure was defined by the analytical solution of the Fick's second law described by Equations (2)-(4).(13) This solution is valid for an infinite slab geometry (thickness much smaller than length and width), constant diffusivity, variable surface concentration of migrant in the packaging due to diffusion to a solution of limited volume, and initial concentration in the food equal to zero. Given the dimensions and formats of most packages, these assumptions hold true and this model is accepted and commonly used to describe the migration of packaging components into foods and food simulants. ${ }^{(8)}$

$$
\frac{C(t)}{C_{\infty}}=1-\sum_{n=1}^{\infty} \frac{2 \alpha(1+\alpha)}{1+\alpha+\alpha^{2} q_{n}^{2}} \exp \left(-D^{P} t \frac{q_{n}^{2}}{L^{2}}\right)
$$


where,

$$
\alpha=\frac{V^{F} / V^{P}}{K_{P}^{F}}
$$

and $q_{n}$ are the nonzero positive roots of

$$
\tan \left(q_{n}\right)=-\alpha q_{n} .
$$

$C(t)$ is the concentration of the migrant in the food at time $t$, and $C_{\infty}$ is the concentration at equilibrium, that is, for very long time of contact between the food and the package. The model parameters are the diffusion coefficient $\left(D^{P}\right)$ and the partition coefficient $\left(K_{P}^{F}\right)$.

The variables $L, V^{F}$, and $V^{P}$ are, respectively, the packaging material thickness, the volume of food, and the volume of packaging material (i.e., the surface area times the thickness), and are all related to the packaging geometry.

When the objective is to assess compliance, the model parameters $\left(D^{P}\right.$ and $\left.K_{P}^{F}\right)$ are estimated in order to yield worst-case single-point migration predictions. However, the model is affected by uncertainties in sampling and measurements in experimental data used to develop the model, namely, to estimate $D^{P}$ and $K_{P}^{F}$, and uncertainty due to extrapolation from conditions of experiments on which the model was based to other conditions for which predictions are required. ${ }^{(12)}$ In this work kinetics experiments were independently carried out to generate a distribution of estimates for these mass-transfer parameters, providing a more realistic and accurate result as to the probability of migration occurrence in a specific packaging system. The values for these coefficients were obtained at three temperatures and the temperature dependence was considered to be described by an Arrhenius model.

$$
\begin{aligned}
& D^{P}=D_{o} \exp \left(-\frac{E_{D}}{R T}\right), \\
& K_{P}^{F}=K_{o} \exp \left(-\frac{E_{K}}{R T}\right),
\end{aligned}
$$

where $T$ is the absolute temperature. Equation (7) describes the model assumed to describe the influence of temperature on the equilibrium concentration of the migrant in the food simulant.

$$
C_{\infty}=C_{o}+\frac{E_{C}}{T}
$$

The software Statistica (StatSoft, Inc.) was used to estimate the migration model coefficients $\left(D^{P}\right.$,
Table I. Specifications of the Model Inputs Distributions

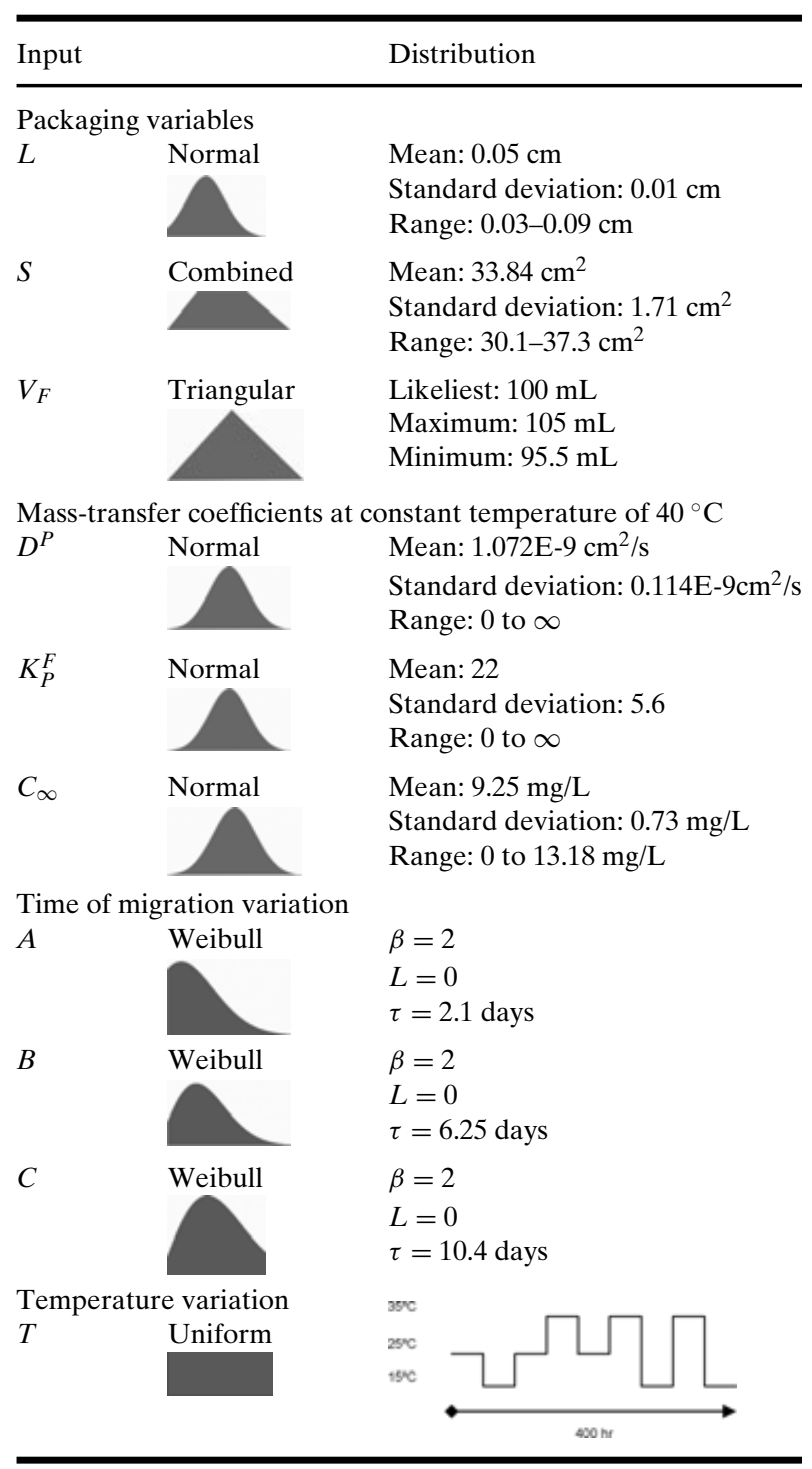

$K_{P}^{F}$, and $C_{\infty}$ ) of each kinetics experiment and to estimate the parameters of the Arrhenius equations discussed earlier, by nonlinear estimation and least squares as loss function.

Table I presents the specifications of the distributions of the model inputs. All inputs were considered independent except those related to the packaging geometry. They were chosen on the basis of the experimental values obtained and expert judgment from real-life data.

The package thickness was described by a normal distribution fitted from experimental results from 1,000 readings in 10 packages from the same lot, 
truncated with minimum and maximum experimental values. The package surface area was described by a distribution fitted from experimental results from the trial with 18 replicates, truncated with minimum and maximum experimental values, the distribution chosen was a triangular distribution combined with a uniform distribution at the central values. The volume of simulant was described by a triangular distribution with the volume of simulant used in the experiments as the likeliest value. A maximum value was defined as $5 \%$ of the likeliest. The minimum value was defined according to the tolerable negative error set by the European law relating to the making-up by volume of certain prepackaged liquids. ${ }^{(14)}$

For the runs where temperature was considered constant, the diffusion and the partition coefficients were described by a normal distribution truncated for only positive values; mean and standard deviation estimated from the experimental trial with the nine replicates obtained at $40{ }^{\circ} \mathrm{C}$. Equilibrium concentration was described by a normal distribution truncated for only positive values and maximum value considering that all amount of migrant initially present in the material migrates into the food simulant; mean and standard deviation estimated from the experimental trials.

For the time of contact, two options were considered: (1) constant and equal to 400 hours, thus the model output was the migration value after a certain fixed period of time and (2) variable according to Weibull distributions corresponding to different scenarios of time elapsed between the filling and consumption (Table I). The distributions were truncated at a minimum of 24 hours (allowance for transportation time to the selling point) and a maximum of 400 hours (end of product shelf life/kinetics experiment). In this case, the time of contact was also considered as a parameter with a given variability in order to assess the impact of the storage time on the migration value. This second study was conducted since the analyses of the mass-transfer equations illustrate that the distribution of storage times may drastically change the range of contamination values of packaged food products. ${ }^{(9)}$

Finally, a run considering that the temperature varied during the contact time was performed and a temperature profile with values between $15{ }^{\circ} \mathrm{C}$ and $35{ }^{\circ} \mathrm{C}$ was assumed as an example (Table I). The probability distribution function for the diffusion coefficient was given by Equation (5) with the mean estimate for the Arrhenius parameters $\left(\overline{D_{o}}, \overline{E_{D}}\right)$, the standard error $(\varepsilon)$, and a random number $(R)$ from a normal distribution with zero mean and standard deviation equal to 1 .

$$
\begin{aligned}
\ln \left(D_{o}\right) & =\ln \left(\overline{D_{o}}\right)+\varepsilon \cdot R \\
E_{D} & =\overline{E_{D}}+\varepsilon \cdot R
\end{aligned}
$$

The same approach was followed for the partition coefficient and for the equilibrium concentration. The values of this latter were truncated for positive and lower than the maximum concentration obtained if total migration would occur.

The software Crystal Ball 7.2.2. (Decisioneering, Inc., Denver, CO, USA) was used to perform the model calculations and to propagate the variability and uncertainty through the model. MC simulation was used as sampling method with 10,000 trials for each run. All case studies were run with this sample size, suggested in principles of good practice for MC risk assessments. ${ }^{(15)}$ Descriptive statistics were calculated from the migration estimates generated by the model. The migration values obtained were fit to probability distributions by the maximum likelihood method and the goodness of fit assessed by the Anderson-Darling (A-D) test. Sensitivity analysis was performed by computing rank correlation coefficients between every input and every output. The results are provided as contribution to variance by squaring the rank correlation coefficients and normalizing them to $100 \%$.

\section{RESULTS AND DISCUSSION}

\subsection{Constant Migration Time and Constant Temperature}

Fig. 1 presents the results obtained in two of the nine migration experiments at $40{ }^{\circ} \mathrm{C}$ and the respective curve of the Fick's law solution fitting, as examples. Similar curves were obtained for each replicate and each temperature. The model in Equation (2) described the data well and the results for the diffusion and partition coefficients obtained for each experiment are presented in Table II. Data presented relatively low dispersion within each temperature.

Fig. 2 shows the distribution of migration values found when the model is submitted to MC simulation with 10,000 runs: the values ranged from 5.68 up to $11.48 \mathrm{mg} / \mathrm{L}$. Table III presents the corresponding statistics. The average was $8.69 \mathrm{mg} / \mathrm{L}$ and the variance $0.64 \mathrm{mg} / \mathrm{L}$. The data were fit to different probability distributions (see Table IV) and the beta 
Fig. 1. Migration of Irgafos 168 from HDPE into isoctane at $40{ }^{\circ} \mathrm{C}$. Results of two replicates $(\boldsymbol{\square}, \times)$ and fitting the experimental data to solution of Fick's law (_).

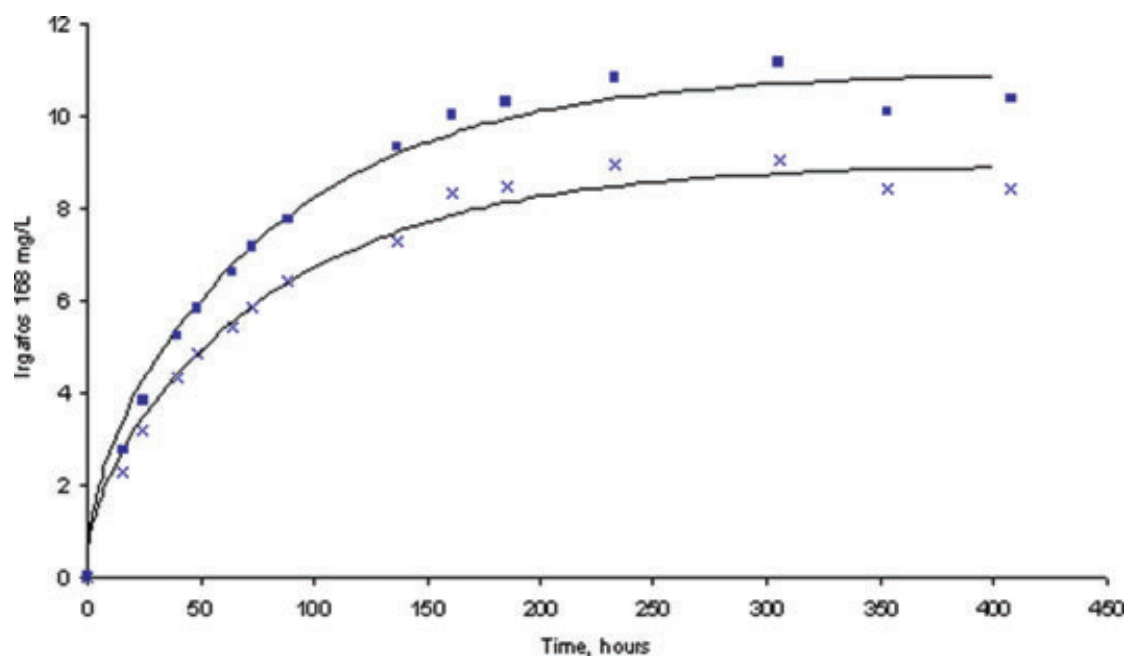

Table II. Experimental Results for Diffusion and Partition Coefficients and Concentration at Equilibrium of Irgafos 168

\begin{tabular}{lccrr}
\hline Temperature & Replicate & $\begin{array}{c}D^{P} \times 10^{9}, \\
\mathrm{~cm}^{2} / \mathrm{s}\end{array}$ & $K_{P}^{F}$ & $\begin{array}{r}C_{\infty}, \\
\mathrm{mg} / \mathrm{L}\end{array}$ \\
\hline $40{ }^{\circ} \mathrm{C}$ & 1 & 1.082 & 20.8 & 9.4 \\
& 2 & 1.091 & 13.9 & 10.4 \\
& 3 & 0.843 & 14.0 & 10.3 \\
& 4 & 1.091 & 29.2 & 8.4 \\
& 5 & 0.933 & 18.5 & 9.7 \\
& 6 & 1.129 & 25.3 & 8.8 \\
& 7 & 1.136 & 27.4 & 8.6 \\
& 8 & 1.214 & 24.4 & 8.9 \\
& $9{ }^{\circ} \mathrm{C}$ & 1.128 & 24.6 & 8.9 \\
& 1 & 0.167 & 56.9 & 5.7 \\
& 2 & 0.160 & 39.3 & 7.1 \\
& 3 & 0.155 & 52.6 & 6.1 \\
& 4 & 0.149 & 41.1 & 7.2 \\
$8{ }^{\circ} \mathrm{C}$ & 5 & 0.127 & 34.3 & 7.7 \\
& 1 & 0.060 & 218.4 & 2.9 \\
& 2 & 0.055 & 244.2 & 2.7 \\
& 3 & 0.057 & 274.4 & 2.4 \\
& 4 & 0.057 & 271.7 & 2.4 \\
& 5 & 0.055 & 253.8 & 2.6 \\
\hline
\end{tabular}

and normal distributions described the forecasted migration very well. With the distribution function parameters, or directly from Fig. 2, it is very easy to estimate the probability (the risk) of a given threshold being exceeded. For example, there is a risk of $10 \%$ of a package to yield a migration value of $9.72 \mathrm{mg} / \mathrm{L}$ or higher after 400 hours of migration.

Fig. 3a presents the sensitivity chart, which quantifies how much of the variability of the output is explained by the variability of each input, not only in terms of the range of possible outcomes but also in terms of the likelihood of occurrence of those outcomes. The equilibrium concentration is the most dominant input, explaining $74 \%$ of the migration variance. This may not be surprising since this analysis focused on the end of the product shelf life, defined here as the end of the migration experiment when the system achieved equilibrium. In these conditions, thickness contributes $23.4 \%$ of the variance and the other packaging geometry parameters only $0.1 \%$. Diffusion and the partition coefficients account for $2.5 \%$ of the migration variance.

\subsection{Variable Migration Time and Constant Temperature}

In real life, however, the packages will be purchased and consumed with different shelf times, corresponding to different contact times between the packaging materials and the food, thus corresponding to different migration times. A minimum of 24 hours of contact is expected due to transportation from the producer to the selling point and then, after purchasing, to the consumer home. A maximum of 400 hours, corresponding to the end of the migration experiment and considered as the product shelf life, was defined for this study. To describe the distribution of time values, Weibull distributions were defined based on previous work. ${ }^{(10)}$ The different scenarios (Table I) considered increasing average time of consumption. These distributions of consumption times were input on the migration model (Equation (2)), which was submitted to random simulation as previously described.

The statistics for the forecasted migration values are presented in Table III: an increase from 2 to 


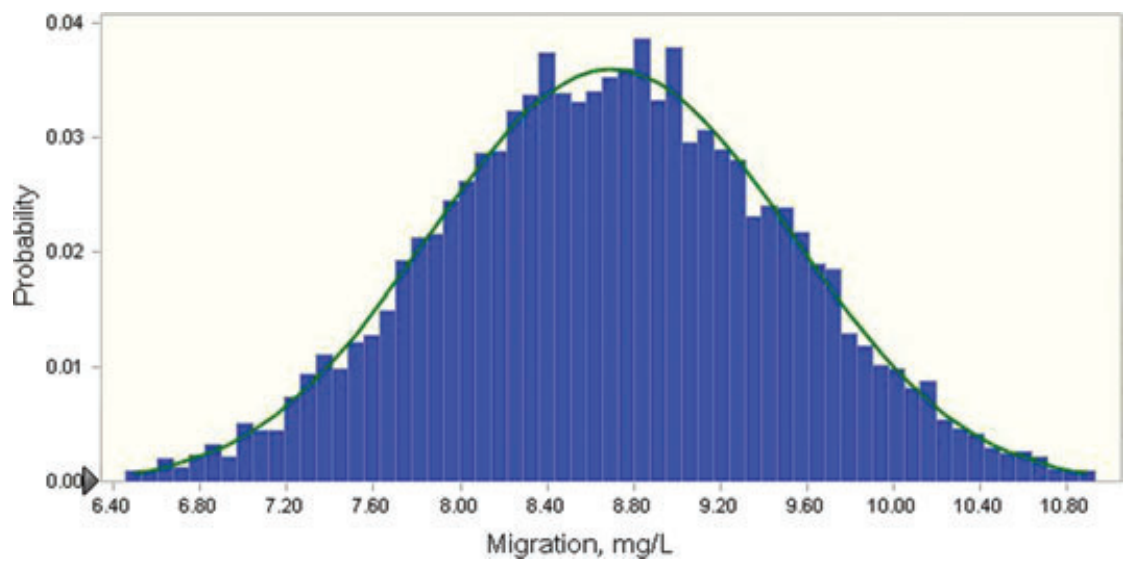

\begin{tabular}{|c|c|c|c|c|c|}
\hline \multirow{2}{*}{$\begin{array}{l}\text { Statistics } \\
\text { Migration Scenario }\end{array}$} & \multicolumn{5}{|c|}{ Migration, mg/L } \\
\hline & 400 hours & A & B & $\mathrm{C}$ & $\begin{array}{c}\text { Variable } \\
\text { Temperature }\end{array}$ \\
\hline Mean & 8.69 & 5.08 & 6.65 & 7.38 & 4.25 \\
\hline Median & 8.70 & 4.98 & 6.64 & 7.48 & 3.50 \\
\hline Standard deviation & 0.80 & 0.93 & 1.32 & 1.34 & 3.31 \\
\hline Variance & 0.64 & 0.86 & 1.75 & 1.78 & 10.98 \\
\hline Skewness & -0.0061 & 0.5470 & 0.0255 & -0.3165 & 0.7391 \\
\hline Kurtosis & 2.87 & 3.24 & 2.53 & 2.71 & 2.62 \\
\hline Coefficient of variability & 0.0920 & 0.1825 & 0.1991 & 0.1809 & 0.7793 \\
\hline Minimum & 5.68 & 2.62 & 2.66 & 2.72 & 0.00 \\
\hline Maximum & 11.48 & 9.48 & 11.11 & 11.34 & 13.17 \\
\hline Range width & 5.80 & 6.86 & 8.45 & 8.61 & 13.17 \\
\hline Mean standard error & 0.01 & 0.01 & 0.01 & 0.01 & 0.03 \\
\hline
\end{tabular}

\begin{tabular}{|c|c|c|c|}
\hline Scenarios & Distribution & A-D ${ }^{1}$ & Parameters \\
\hline \multirow[t]{3}{*}{400 hours } & Beta & 0.2070 & $\begin{array}{l}\text { Min. }=3.40 ; \text { Max- }=13.88 ; \alpha=21.21309 \\
\quad \beta=20.78126\end{array}$ \\
\hline & Normal & 0.4326 & $\mu=8.69 ; \sigma=0.80$ \\
\hline & Log-normal & 8.4159 & $\mu=8.69 ; \sigma=0.81$ \\
\hline \multirow[t]{3}{*}{ A } & Beta & 0.3764 & $\begin{array}{l}\text { Min. }=2.61 ; \operatorname{Max} .=15.08 ; \alpha=5.48291 \\
\quad \beta=22.22216\end{array}$ \\
\hline & Log-normal & 2.2664 & $\mu=5.08 ; \sigma=0.92$ \\
\hline & Weibull & 27.3071 & $L=2.50 ; \tau=2.89 ; \beta=3.04332$ \\
\hline \multirow[t]{3}{*}{ B } & Beta & 0.2857 & $\begin{array}{l}\text { Min. }=2.42 ; \operatorname{Max} .=11.08 ; \alpha=4.7365 \\
\quad \beta=4.95737\end{array}$ \\
\hline & Weibull & 2.3643 & $L=2.32 ; \tau=4.81 ; \beta=3.64099$ \\
\hline & Normal & 7 & $\mu=6.65 ; \sigma=1.32$ \\
\hline \multirow[t]{3}{*}{$\mathrm{C}$} & Beta & 1.6647 & $\begin{array}{l}\text { Min. }=1.16 ; \operatorname{Max} .=10.84 ; \alpha=7.11674 \\
\quad \beta=3.95687\end{array}$ \\
\hline & Weibull & 5.6001 & $L=2.00 ; \tau=5.89 ; \beta=4.57572$ \\
\hline & Normal & 24.6026 & $\mu=7.38 ; \sigma=1.34$ \\
\hline \multirow{3}{*}{$\begin{array}{l}\text { Variable tem- } \\
\text { perature }\end{array}$} & Weibull & 67.3936 & $L=-0.05 ; \tau=4.61 ; \beta=1.29646$ \\
\hline & Log-normal & 72.99 & $L=-1.04 ; \mu=4.36 ; \sigma=4.18$ \\
\hline & Normal & 217.1668 & $\mu=4.25 ; \sigma=3.31$ \\
\hline
\end{tabular}

${ }^{1}$ The lower the A-D parameters, the better the fit.
Fig. 2. Distribution of migration values for constant migration time equal to 400 hours and temperature at $40^{\circ} \mathrm{C}$.
Table III. Statistics of Migration Estimates
Table IV. Fitting Statistics of Common Frequency Distribution Models to the Data Generated for the Different Migration Scenarios 


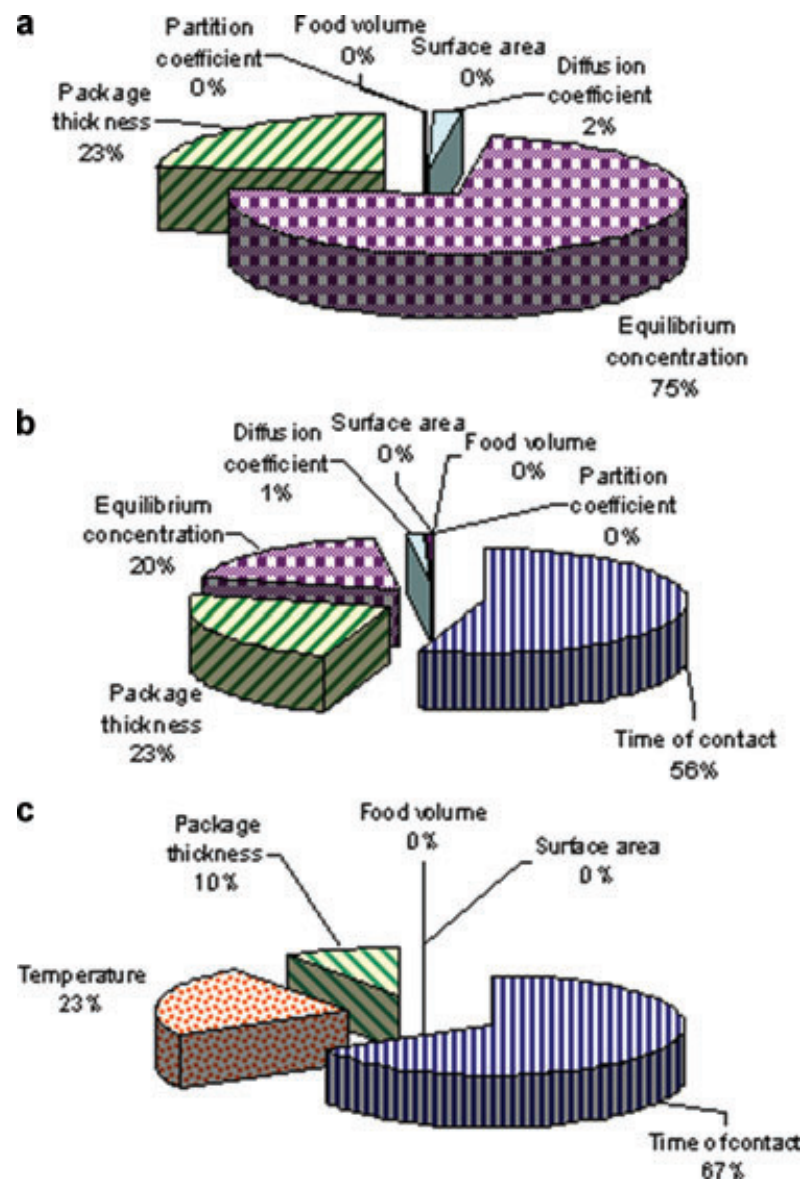

Fig. 3. Percentage contribution of system factors to the variance of migration results: (a) migration at end of shelf life; (b) consumption time described by Weibull distribution (c); (c) temperature changing during storage.

10 days on average migration time yields an increase from 5.1 to $7.4 \mathrm{mg} / \mathrm{L}$ in migration average value. The range was also wider; the migration values were more spread. Skewness decreased and became negative for higher average migration times (the distribution becomes skewed to the left).

The fits of different distributions to the migration results obtained in each scenario simulated are given in Table IV. The distributions were in all cases far from being normal. The beta model gave the best fit according to the A-D test, followed by the Weibull model except for scenario A of varying migration time. The sensitivity chart for scenario $\mathrm{C}$ is shown in Fig. 3b. As can be seen, the time of migration accounts for $56 \%$ of the variance of the data. Packaging thickness represents $23 \%$ and the equilibrium concentration, approximately $20 \%$. These results indicate that a more refined level of exposure assessments may justify a more precise definition of the distribution of consumption times. The risk analysis can be performed directly from the histogram (Fig. 4) or from the distributions describing the migration data. If, for example, a threshold of $9 \mathrm{mg} / \mathrm{L}$ is defined, the risk for this migration value to be exceeded is lower than $1 \%$ in scenario $\mathrm{A}$, and increases to $3.5 \%$ and $11 \%$ for scenarios B and C, respectively. This means that, if the average consumption time increases from 4 days to 8 days, the risk of having a package with a migration value of $9 \mathrm{mg} / \mathrm{L}$ or higher increases from less than $1 \%$ to $11 \%$.

\subsection{Variable Migration Time and Temperature}

To assess the influence of a changing temperature on the migration process, a temperature profile was assumed as described by three levels of temperature $\left(15{ }^{\circ} \mathrm{C}, 23{ }^{\circ} \mathrm{C}\right.$, and $\left.35^{\circ} \mathrm{C}\right)$ held for equal periods of time. Although data for only three temperatures were available, the influence of temperature on the diffusion and partition coefficients and on the equilibrium concentration was assessed
Fig. 4. Distribution of migration values for migration time varying according to a Weibull distribution and constant temperature.

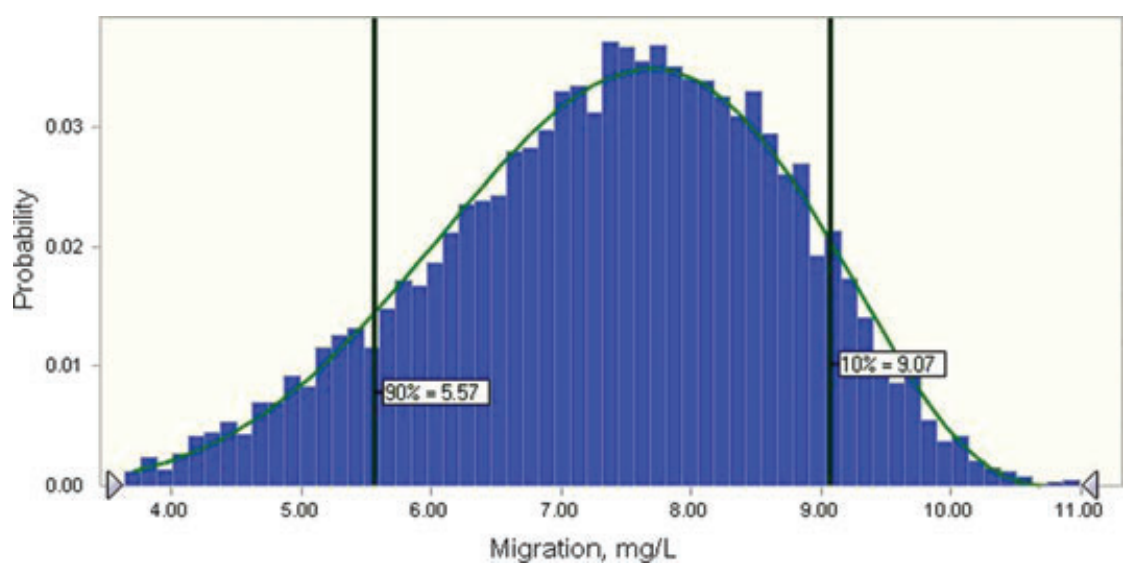




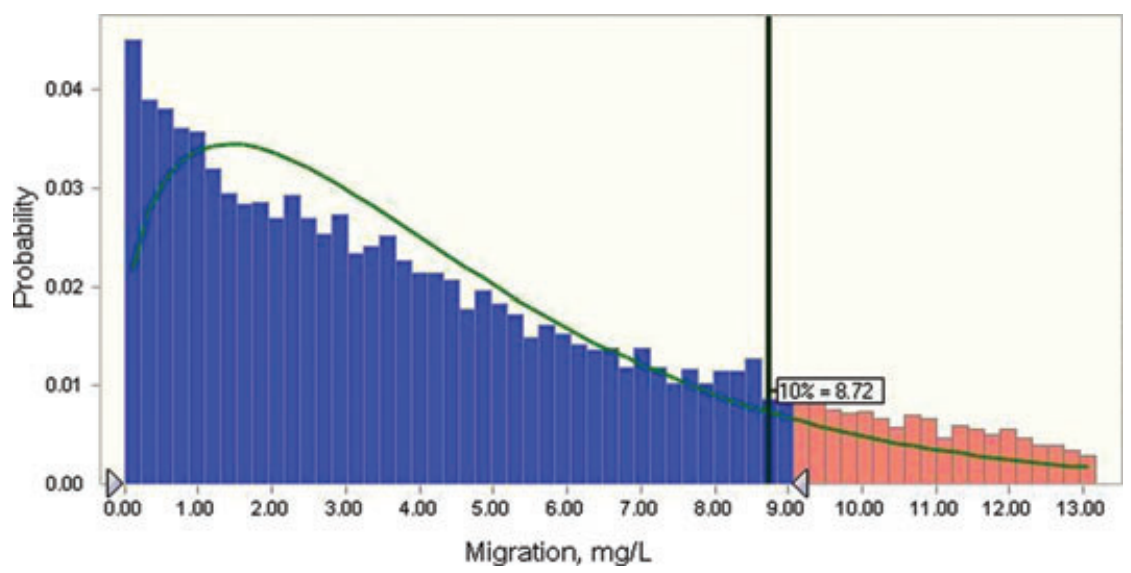

Fig. 5. Distribution of migration values for migration time varying according to a Weibull distribution and changing temperature.

according to Equations (5)-(7). The resulting estimates for these model parameters are presented in Table V. The goodness of fit was assessed by the $R^{2}$, which was in all cases higher than 0.9. These relationships were included in the migration model, which was run for a contact time scenario corresponding to case $\mathrm{C}$ in Table I.

Fig. 5 presents the distribution of values found for the migration. The values ranged from 0 to $13.2 \mathrm{mg} / \mathrm{L}$ with a mean of $4.25 \mathrm{mg} / \mathrm{L}$. The statistics of the estimates are also presented in Table III. The mean migration for this scenario is lower than what could be expected since periods of lower temperature of contact occur. This decreases the migration rate thus yielding lower concentration values of the migrant in the food as compared to the other scenarios of simulation. In addition, the range of values is much higher as could also be expected given the wide range of temperatures considered. The sensitivity chart for this scenario is shown in Fig. 3c. The time of migration accounts for more than $60 \%$ of the variance of the data and temperature accounts for approximately $23 \%$. The probability distribution function that better describes these data is the Weibull function (Table IV).

\section{CONCLUSIONS}

This work presents a mathematical approach to assess the risk of migration of packaging components. It can be applied to a specific migrant/ packaging/food system to optimize the material formulation, for example, taking into account the variability expected in the system parameters and the impact this has on the probability of obtaining a predefined migration threshold. Furthermore, when combined with food consumption data it allows for
Table V. Parameters for Models Describing the Diffusion and Partition Coefficients and Equilibrium Concentration as a

Function of Temperature

\begin{tabular}{ccccc}
\hline & Parameter & Mean Estimate & Standard Error & $R^{2}$ \\
\hline$D^{P}$ & $\overline{\ln D_{o}}$ & 5.75 & 1.21 & 0.969 \\
& $\overline{E_{D}}$ & 8,294 & 361 & \\
$K_{P}^{F}$ & $\overline{\ln K_{o}}$ & -17.97 & 1.64 & 0.913 \\
& $\overline{E_{K}}$ & $-6,550$ & 491 & \\
$C_{\infty}$ & $\overline{C_{o}}$ & 69.3 & 4.40 & 0.922 \\
& $\overline{E_{C}}$ & $-18,714$ & 1,317 & \\
\hline
\end{tabular}

estimation of exposure of consumer to packaging migrants.

The time of consumption, that is, the time elapsed between package filling and food consumption, is an important source of variability in migration values that should be taken into consideration in exposure studies. This variable is highly dependent on consumer shopping habits. In a worst-case scenario (maximum time of contact to the end of shelf life), equilibrium concentration was the dominant factor causing variability in migration values. Variability in the diffusion coefficient (process kinetics) showed a minor influence on the variability of migration. Depending on the range, temperature can be an important factor contributing to variability of the migration.

This study demonstrates how a simple tool using ubiquitous software (e.g., MS Excel) can be used for probabilistic analysis of migration and exposure assessment. This approach may be particularly useful in interdisciplinary studies to assess the impact of different scenarios related to consumer behavior and perception, noting that it is fast and does not require an extensive step of concentration data collection. 


\section{REFERENCES}

1. EFSA. Transparency in risk assessment-Scientific aspects. EFSA Journal, 2009; 1051:1-22.

2. Poças MFF, Hogg T. Exposure assessment of chemicals from packaging materials in foods: A review. Trends in Food Science and Technology, 2007; 18:219-230.

3. Holmes MJ, Hart A, Northing P, Oldring PKT, Castle L. Dietary exposure to chemical migrants from food contact materials: A probabilistic approach. Food Additives and Contaminants, 2005; 22(10):907-919.

4. Oldring PKT, Castle L, Hart A, Holmes MJ. Migrants from food cans revisited: Application of a stochastic model for a more realistic assessment of exposure to BADGE. Packaging Technology and Science, 2006; 19:121-137.

5. Castle L, Hart A, Holmes MJ, Oldring PKT. Approach to stochastic modelling of consumer exposure for any substance from canned foods using simulant migration data. Food Additives and Contaminants, 2006; 23(5):528-538.

6. Dickson-Spillmann M, Siegrist M, Keller C, Wormuth M. Phthalate exposure through food and consumers' risk perception of chemicals in food. Risk Analysis, 2009; 29(8):1170-1181.

7. Vitrac $\mathrm{O}$, Hayert M. Risk assessment of migration from packaging materials into foodstuffs. AIChE Journal, 2005; 51(4):1080-1095.

8. Poças MFF, Oliveira JC, Oliveira FAR, Hogg T. A critical survey of predictive mathematical models for migration from packaging. Critical Reviews in Food Science and Nutrition, 2008; 48:1-16.

9. Vitrac O, Leblanc JC. Consumer exposure to substances in plastic packaging. I. Assessment of the contribution of styrene from yogurt pots. Food Additives and Contaminants, 2007; 24(2):194-215.

10. Vitrac O, Challe B, Leblanc JC, Feigenbaum A. Contamination of packaged food by substances migrating from a directcontact plastic layer: Assessment using a generic quantitative household scale methodology. Food Additives and Contaminants, 2007; 24(1):75-94.

11. Helmroth E, Varekamp C, Dekker M. Stochastic modelling if migration from polyolefins. Journal of the Science of Food and Agriculture, 2005; 85:909-916.

12. EFSA. Guidance of the scientific committee to a request from EFSA related to uncertainties in dietary exposure assessment. EFSA Journal, 2006; 438:1-54.

13. Crank J. The Mathematics of Diffusion, 2nd ed. Oxford, UK: Oxford University Press, 1986.

14. Council Directive of 23 November 1979 amending Directive 75/106/EEC on the approximation of the laws of the Member States relating to the making-up by volume of certain prepackaged liquids (79/1005/EEC). Official Journal, 1979; 308:2529.

15. Burmester DE, Anderson PD. Principles of good practice for the use of Monte Carlo techniques in human health and ecological risk assessment. Risk Analysis, 1994; 14: 477-481. 